\title{
The dilution of parents' nonmaterial resources in stepfamilies: The role of complex sibling configurations in parental involvement
}

Citation for published version (APA):

de Leeuw, S. G., Kalmijn, M., \& van Gaalen, R. (2022). The dilution of parents' nonmaterial resources in stepfamilies: The role of complex sibling configurations in parental involvement. Social Forces, 100(4), 1671-1695. https://doi.org/10.1093/sf/soab088

Document status and date:

Published: 01/06/2022

DOI:

10.1093/sf/soab088

Document Version:

Publisher's PDF, also known as Version of record

Document license:

Taverne

Please check the document version of this publication:

- A submitted manuscript is the version of the article upon submission and before peer-review. There can be important differences between the submitted version and the official published version of record.

People interested in the research are advised to contact the author for the final version of the publication, or visit the DOI to the publisher's website.

- The final author version and the galley proof are versions of the publication after peer review.

- The final published version features the final layout of the paper including the volume, issue and page numbers.

Link to publication

\footnotetext{
General rights rights.

- You may freely distribute the URL identifying the publication in the public portal. please follow below link for the End User Agreement:

www.umlib.nl/taverne-license

Take down policy

If you believe that this document breaches copyright please contact us at:

repository@maastrichtuniversity.nl

providing details and we will investigate your claim.
}

Copyright and moral rights for the publications made accessible in the public portal are retained by the authors and/or other copyright owners and it is a condition of accessing publications that users recognise and abide by the legal requirements associated with these

- Users may download and print one copy of any publication from the public portal for the purpose of private study or research.

- You may not further distribute the material or use it for any profit-making activity or commercial gain

If the publication is distributed under the terms of Article $25 \mathrm{fa}$ of the Dutch Copyright Act, indicated by the "Taverne" license above, 


\title{
The Dilution of Parents' Nonmaterial Resources in Stepfamilies: The Role of Complex Sibling Configurations in Parental Involvement
}

\author{
Suzanne G. de Leeuw, Maastricht University, The Netherlands \\ Matthijs Kalmijn, Netherlands Interdisciplinary Demographic Institute \\ (NIDI)-KNAW/University of Groningen, The Netherlands \\ Ruben van Gaalen, Statistics Netherlands, The Netherlands, \\ University of Amsterdam, The Netherlands
}

\begin{abstract}
$\mathrm{t}$ has been argued that an increase in the number of siblings means that there are fewer parental investments made per child (resource dilution hypothesis). Yet, these studies are mostly based on biological two-parent families in which it can be assumed that parental resources are distributed more or less equally across siblings. This assumption does not hold in the complex family structure of a stepfamily where not all siblings are biologically related and living in the same household. Since more and more children are growing up in stepfamilies, a distinction between sibling types (ful$\mathrm{l} / \mathrm{half} / \mathrm{step}$ ) is needed. In this study, we focus on the dilution of nonmaterial resources (i.e., parental involvement) and use the OKiN dataset to examine paternal $(n=1,077)$ and maternal $(n=1,369)$ resources separately. In this way, this study provides the first comprehensive overview of the dilution of parental resources in stepfamilies. While maternal resources are mostly diluted by full siblings, paternal resources are diluted by all sibling types (full, half, and step). We reflect on the implications of these results for the literature on sibship size as well as the literature on social mobility.
\end{abstract}

\section{Introduction}

It is well known that the number of siblings in a family is negatively associated with children's educational outcomes as well as with contact frequency, closeness, and exchange of support between parents and (adult) children (e.g., Lu and Treiman 2008; Wiemers et al. 2019). Based on the wide variety of these outcome

Acknowledgments: This work was supported by the European Research Council under the European Union's Horizon 2020 research and innovation program (Grant 669334).

Direct correspondence to Suzanne G. de Leeuw, Research Centre for Education and the Labour Market (ROA) - Education Lab/Maastricht University, Tongersestraat 49, 6211 LM Maastricht, The Netherlands; e-mail: s.deleeuw@maastrichtuniversity.nl. 
variables, it is clear that sibship size is relevant to many key topics in the sociological discipline, such as inequality, cohesion, and well-being. Explanations for the negative association between sibship size and the aforementioned outcome variables are usually based on the principles of resource dilution (Blake 1989; Downey 1995). The general argument is that there are fewer parental resources available per person if they have to be shared with a larger number of siblings. This argument is based on a zero-sum game that is applicable to all finite resources, including material resources as well as nonmaterial resources, such as time, attention, and energy.

Despite the popularity of the resource dilution hypothesis, the literature has been challenged by a causality debate. Many researchers have focused on methodological advancement and used twin studies, instrumental variables, and longitudinal data in their attempts to establish the causal nature of sibship size effects. Based on these methods, some state that the observed sibship size effects in regular regression analyses are spurious and in reality a reflection of other family background characteristics (e.g., Black, Devereux, and Salvanes 2005; Workman 2017). Yet, using similar methods, other researchers find support for the resource dilution hypothesis (e.g., Conley and Glauber 2006; Li, Zhang, and Zhu 2008). Rather than adding directly to this methodological debate, we aim to offer a renewed perspective on the meaning of sibship size and its consequences for parental resources by focusing on a significant demographic shift which so far has received insufficient attention in the sibship size literature: the increase in family complexity.

Accompanying an upward trend in divorces and separations, remarriage, stepfamilies, and multipartner fertility have become increasingly common (Tach 2015). As a result, many children grow up with half and stepsiblings in their family. Remarkably little is known about how this has changed the role of sibship size. Most current studies focus on full siblings and the context of biological twoparent families, while there are theoretical reasons to believe that distinctions between full, half, and stepsiblings are relevant. To start, studies on sibship size in biological two-parent families assume that there is no systematic favoritism in modern societies (e.g., Blake 1989). More recent studies have already questioned this assumption, also in biological two-parent families (e.g., Suitor, Sechrist, and Pillemer 2007). However, it is likely that an unequal distribution of resources is especially endemic in stepfamilies, in which parents sometimes have biological as well as stepchildren and where it is not self-evident that parents reside with all of their children. Additionally, large age differences between siblings are more common in stepfamilies than in biological two-parent families, and this could change the dilution of resources considerably. This study aims to unravel how complex sibling configurations in the growing number of stepfamilies are related to the possible dilution of parents' nonmaterial resources.

The focus on nonmaterial resources is an important and distinctive feature of this study. In line with previous studies in the literature on social and human capital in families, we use indicators of parental involvement to measure the presence of nonmaterial resources (e.g., McNeal 1999). Parental involvement is associated with important outcomes, such as children's well-being and the exchange of support between parents and children later in life (Benner, Boyle, and Sadler 
2016; Kalmijn 2014). Additionally, parental involvement offers a more direct test of the assumed mechanism that children receive fewer parental investments when the number of siblings increases, which underlies the frequently studied association between sibship size and educational attainment.

We use the recently collected dataset Parents and Children in the Netherlands (OKiN: Ouders en Kinderen in Nederland) (Kalmijn et al. 2018) and Dutch administrative data to study how the presence of full, half, and stepsiblings is related to the involvement of both biological parents. The dataset contains a sample of respondents between twenty-five and forty-six years old (anchors) and their (step)parents (alters). Stepfamilies are systematically oversampled, which makes this dataset particularly suitable for our study. All respondents are born in the first unions of their parents. No distinction is made between parents who were married or cohabiting prior to their divorce or separation. Unmarried parenthood by cohabiting couples is common in the Netherlands, and these unions are also relatively stable (Van Gaalen, Van Houdt and Poortman, 2019). To improve readability, we use the term separation throughout this article to refer to the end of a relationship regardless of this relationship's legal status. Because respondents report separately on the involvement of biological fathers and mothers during their childhood (retrospectively), we are able to analyze paternal $(n=1,077)$ and maternal $(n=1,369)$ resources separately. Our samples consist of children whose parents were together when they were born but separated and formed new partnerships by the time the child was fifteen. Altogether, these data enable us to create the first comprehensive overview of how sibship size and complex sibling configurations in stepfamilies are associated with nonmaterial parental investments in children. With this approach, we bring the literature on resource dilution into the present era of family complexity.

\section{Theory}

The resource dilution hypothesis is the most frequently used theory when the association between sibling configurations and parental resources is studied. It is appealing because it offers a simple and intuitive theory: An increase in the number of siblings means that a smaller share of parental resources is available per child (Blake 1989; Downey 1995). We argue that the implicit assumption that parents distribute their resources more or less equally over their offspring does not hold in stepfamilies. Two theoretical arguments are distinguished to explain why parents in stepfamilies invest more resources in some children than in others: (1) arguments related to the biological bond between parents and children and (2) arguments based on the literature on kinkeeping and common coresidence patterns.

Throughout this study, we distinguish between full, half and stepsiblings. The terms paternal and maternal are used to clarify whether siblings entered the family via the repartnering of the father (paternal) or the mother (maternal). We only study the involvement of the biological parents, so the terms mother, father, and parents are used to refer to the biological parents of our respondents. An overview of the actors in stepfamilies is visualized in figure 1. All hypotheses are formulated from the perspective of the children in the first union of the 
Figure 1. Stepfamily structure.

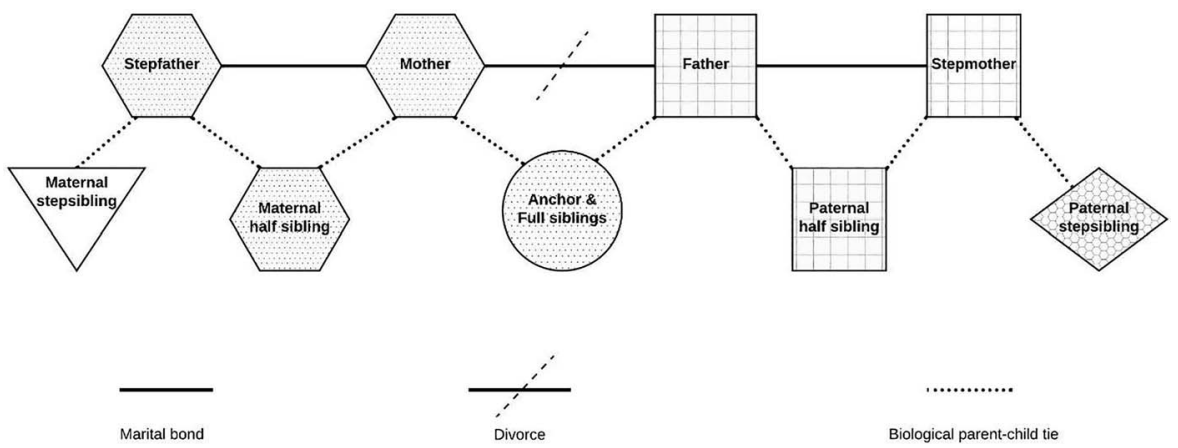

Note: A similar background pattern indicates that actors are, based on the most common coresidence arrangements and kinkeeping mechanisms, likely to share a household. A similar shape indicates that actors belong to the same nuclear family (two partners and their biological child(ren)).

parents. The theories we use focus on the question why parents might invest more time and energy in some of their children. If it is true that parental investments differ between different types of children, it means that some siblings dilute parental resources more strongly than others. Therefore, we translate theories about parental investments in children into hypotheses about the siblings of our respondents. Finally, we formulate our hypotheses in terms of parental involvement. For example, our baseline hypothesis is that all siblings dilute resources. If we formulate this in terms of parental involvement, we get the following hypothesis:

The number of siblings-full, half and step-reduce the levels of parental involvement per child (baseline hypothesis).

There are reasons to expect that some siblings dilute resources more strongly than others. An important argument for parents to invest resources in children is based on the biological bond between them. Evolutionary theory suggests that parental investments are a manifestation of a human instinct to increase children's survival chances and (reproductive) success (Emlen 1995; Schnettler and Steinbach 2011). As a result, parents are mostly involved in the socialization of their own biological offspring. This pattern is not necessarily the result of rational and conscious decisions, but rather a product of mechanisms favored by evolution. For example, several studies show that parents are able to recognize their own offspring and invest more in children they recognize based on visual and olfactory (smell) similarity (Alvergne, Faurie, and Raymond 2009). The importance of a biological tie is also reflected in societal norms that regulate our day-to-day behavior. There are strong norms that biological family members ought to take care of each other. In the nuclear family, this works in both directions: Parents, and especially mothers, are expected to invest as much as possible or needed in their biological offspring and children should take care of their biological parents when they age. While these norms are strong and 
widespread for biological family members, they are more ambiguous for social family members (Cherlin 1978). The differences in norms are confirmed by empirical studies, which show that the perceived obligations toward biological family members are stronger in comparison with stepfamily members, even when controlled for the years in coresidence (Van Houdt, Kalmijn, and Ivanova 2018). Altogether, we expect parents to invest more in biological offspring than in social offspring (i.e., stepchildren). For the children from the first union of the parents (the subjects of this study), this translates into the following hypothesis:

The number of full and half siblings reduce the levels of parental involvement per child more strongly than the number of stepsiblings (biological relatedness bypothesis).

Additionally, the dilution of paternal resources could differ systematically from the dilution of maternal resources. There are two main arguments, which will help us understand why dilution patterns could be gendered: (1) kinkeeping and (2) coresidence. A simple but accurate description of a kinkeeper is the person in the family who makes sure that family members keep in touch with each other (Rosenthal 1985). In practice, it means that someone organizes family outings and visits and buys birthday presents, for example. In this way, people can also enable the relationship between their partner and their children. Coresidence shapes the opportunity structures for the involvement of parents. We argue that the opportunity structure for investments is more favorable if parents and children live together. Moreover, distributing resources between two households could be much more challenging than within households. Both arguments are gendered and identical predictions can be made about the gendered patterns of dilution based on kinkeeping and coresidence.

Based on the literature on kinkeeping and coresidence, it could be expected that separated fathers are more likely to invest in the children of their new union than in the children of their previous union. To start, the kinkeeping role is mostly fulfilled by female members of the family (Di Leonardo 1987). As a result, women (wives and mothers) often play a mediating role in the relationship between fathers and their children. When parents separate, the father will no longer benefit from the kinkeeping role of the mother (Kalmijn 2013). Yet, if a father repartners, a new potential kinkeeper enters his life. An important difference is that this new kinkeeper, the biological father's second partner, will mainly reinforce the ties with the (biological and step) children in his new union. Hence, based on the swap of kinkeepers, it is expected that fathers will have less contact with the children of a previous union and focus more on the children in their new union.

This line of argumentation is reinforced by the most common coresidence patterns. In the birth cohorts we study (1971-1991), a large majority of the children lived with their mother after separation, while visitation arrangements were made to go to the household of the separated father (e.g., one weekend in every fortnight). The residence arrangements of our sample are described in table 1 . About $69 \%$ of the respondents lived only with their mother after separation, while about $6 \%$ lived with their father. A quarter of the sample lived 
Table 1. Living Arrangements of Respondents after Separation.

\begin{tabular}{lcc}
\hline & Maternal stepfamily & Paternal stepfamily \\
\hline Only mother & $68.7 \%$ & $67.0 \%$ \\
\hline Only father & $5.8 \%$ & $5.9 \%$ \\
\hline Other $^{\mathrm{a}}$ & $25.5 \%$ & $26.7 \%$ \\
\hline \hline
\end{tabular}

${ }^{\text {a }}$ Co-parenting arrangement or some years with mother and some years with father.

in a co-parenting arrangement or moved from one parent to the other after a few years. Those in a co-parenting arrangement generally spend most time with their mother. One of the consequences of this common coresidence pattern is that fathers are more likely to have biological children in two different households. In the 1980s and 1990s, fathers often lived in the household with the children of their new partner (paternal half and stepsiblings of the respondents) while they usually did not live (on a daily basis) in the same households as the children of their first union. For such fathers, it was easier to invest in the children from their current union than in those from a previous union.

Since the kinkeeping role is strongly gendered and mostly fulfilled by women, mothers function more often as kinkeepers. Additionally, mothers are less likely to have a partner who functions as a kinkeeper to reinforce the bond between herself and her stepchildren. Based on this logic, she is better able to keep in contact with her biological children from both unions and less likely to invest in her stepchildren. These patterns are again reinforced by the most common coresidence patterns: Mothers often live together with the biological children of their first as well as their second union while stepchildren live mostly elsewhere (with their own biological mother). This means that a mother is less likely to deal with the challenges that emerge when time and attention have to be balanced between two households. Altogether, the arguments on kinkeeping and common coresidence patterns predict that mothers are more likely to invest resources in full and maternal half siblings than in maternal stepsiblings. Based on the reasoning above, two separate hypotheses can be formulated, one for separated fathers' and one for separated mothers' involvement:

The number of paternal half and stepsiblings reduce paternal involvement per child more strongly than the number of full siblings (swapping family bypothesis).

The number of maternal full and half siblings reduce maternal involvement per child more strongly than the number of maternal stepsiblings (identical to biological relatedness hypothesis).

In sum, for the dilution of separated mothers' resources, the notions of kinkeeping and coresidence have the same implications as the notion of biological relatedness. For the dilution of separated fathers' resources, the notions of kinkeeping and coresidence have a different implication than the notion of biological relatedness and an alternative hypothesis is formulated. 
The different hypotheses for paternal and maternal resources reflect the most common gender roles as well as the most common coresidence patterns in the cohorts we study. This means that we do not measure actual coresidence or kinkeeping ties, but that we use the most common kinkeeping and coresidence patterns to predict gendered dilution patterns in our data. Naturally, we know that some families have other gender dynamics and we acknowledge that in more recent cohorts residence arrangements are more diverse and children's likelihood of living with their father is higher. Dilution patterns might change accordingly. Our approach is a useful starting point in the new research field on resource dilution in stepfamilies. Measuring coresidence in stepfamilies, where children often move between different households and where different siblings have different visitation schedules, is extremely complex and beyond the scope of the current study.

For the involvement of fathers, the notions of biology and kinkeeping and coresidence imply different patterns of dilution (as illustrated in table 2). According to the biology hypothesis, full and half siblings dilute resources more strongly than stepsiblings. In contrast, the swapping family hypothesis suggests that half and stepsiblings dilute resources more strongly than full siblings. These two hypotheses can be interpreted as additive rather than contradictory. If we combine the two hypotheses, the presence of paternal half siblings should result in the strongest dilution of resources since they are biologically related to the father and connected via a coresidence and kinkeeping tie, while only one of the mechanisms applies to full siblings (biology) and paternal stepsiblings (kinkeeping/coresidence). Based on the same logic, it is possible to make comparisons between fathers' and mothers' involvement. When looking at table 2, and assuming that both mechanisms play a role, full siblings should have a stronger effect on maternal involvement in the child than on paternal involvement while a similar level of dilution is expected for maternal and paternal half siblings. Finally, stepsiblings should have a stronger effect on paternal involvement than on maternal involvement in the (biological) child. In this way, the idea of a synthesis between the hypotheses is also helpful to understand the differences in the dilution of paternal and maternal resources.

Finally, it could be argued that siblings especially compete for parental resources when they are in need of these resources simultaneously. The larger age differences get, the more often some siblings are already living independently while others are still at home and in need of care. In these cases, the competition for parental resources might be minimal. If parents have children with multiple partners, it is more likely that the children of the first and second union differ substantially in age. As a result, it is more important to control for the number of years children compete for resources when resource dilution in stepfamilies is studied. To take large age differences into account, we create a weighted version of the variables on half and stepsiblings based on the number of years the respondent and the sibling are both minors $(<18)$ and part of the same stepfamily. We do not create a weighted variable for full siblings since large age differences between full siblings in separated families are very uncommon. Additionally, full siblings already compete for resources before the 
Table 2. Expected Effect of Sibling Types on Paternal and Maternal Resources.

\begin{tabular}{|c|c|c|c|c|}
\hline & & Full & Half & Step \\
\hline \multirow[t]{3}{*}{ Mother } & Biology & Dilution & Dilution & No dilution \\
\hline & Kinkeeping & Dilution & Dilution & No dilution \\
\hline & Total ${ }^{\mathrm{a}}$ & Strong dilution & Strong dilution & No dilution \\
\hline \multirow[t]{3}{*}{ Father } & Biology & Dilution & Dilution & No dilution \\
\hline & Kinkeeping & No dilution & Dilution & Dilution \\
\hline & Total ${ }^{\mathrm{a}}$ & $\begin{array}{l}\text { Moderate } \\
\text { dilution }\end{array}$ & Strong dilution & $\begin{array}{l}\text { Moderate } \\
\text { dilution }\end{array}$ \\
\hline
\end{tabular}

${ }^{a}$ In this row, we distinguish strong, moderate, and no dilution. Strong dilution is used if we expect dilution based on biology hypothesis as well as the kinkeeping hypothesis. No dilution describes the situation in which there is no dilution expected in the biology or kinkeeping hypothesis. Moderate dilution refers to the situation that one of both hypotheses predicts dilution while the other does not.

separation. Hence, we argue that accounting for a lack of competition due to age differences is not necessary for full siblings from a theoretical point of view. Yet, we hypothesize that a model in which we weight the variables of half and stepsiblings fits the data better than an unweighted model since the analyses are corrected for the intensity of the competition for resources.

The number of half and stepsiblings weighted by the time respondents and siblings were part of the same stepfamily during childhood $(<18)$ is a better predictor of the levels of parental involvement than the unweighted number of siblings (spacing hypothesis).

\section{Data and Methods}

\section{Data}

We used the dataset Parents and Children in the Netherlands (OKiN: Ouders en Kinderen in Nederland). The data were collected in 2017. OKiN is a multiactor survey among respondents between twenty-five and forty-six years old (anchors) (birth cohorts 1971-1991), their parents and, if applicable, the new partners of their parents (alters). For this study, we relied solely on the data of the anchor respondents. The response rate is $62 \%$, which is high when compared to other Dutch surveys on similar topics. The dataset is based on a representative and register-based sample of the Dutch population. It contains an oversample of children who did not live with both biological parents at age fifteen and children who lived with the new partner of one of their biological parents at age fifteen. As a result, many respondents lived in stepfamilies during childhood. OKiN combines this sampling frame with a wide variety of variables on parental resources. This makes the dataset particularly suitable for our study on the dilution of nonmaterial parental resources in stepfamilies. The OKiN data are 
complemented with information from Dutch administrative data provided by Statistics Netherlands on the presence of full, half, and stepsiblings on the mother's as well as the father's side of the family.

For the purpose of this study, we selected only the 3,390 respondents whose parents were together at birth and separated before the anchor was fifteen years old. 347 respondents who were not born in the first union of their parents were removed from the sample, which lowered the sample size to 3,043. Furthermore, cases in which the order of events did not add up were excluded from the analysis (e.g., half siblings born before the separation). This could be caused by noise in the administrative data, mistakes of respondents or, in some rare cases, by extremely complex family situations. This reduced our sample by another 347 cases to a total of 2,696 . We selected separate samples to study the involvement of fathers and mothers. For the analysis of the nonmaterial investments by the mother, we selected all respondents who had a stepfather at age fifteen $(N=1,369)$. From now on, we refer to these families as maternal stepfamilies since they are formed due to the repartnering of the biological mother of our respondents. When the resources invested by the father are studied, we applied a similar logic and selected all respondents who had a stepmother at age fifteen $(N=1,077)$. These families are called paternal stepfamilies. These samples partly overlap-553 respondents were part of a maternal stepfamily as well as a paternal stepfamily at age fifteen. Note that coresidence (of respondent and (step)parents) is not relevant for our definition of paternal and maternal stepfamilies.

\section{Variables}

\section{Nonmaterial resources}

We focus in this study on the dilution of nonmaterial resources. In line with previous studies in the literature on social and human capital in families, we operationalized nonmaterial resources using indicators of parental involvement (e.g., McNeal 1999). Parental involvement is measured separately for mothers and fathers. Respondents answered five questions about the involvement of each parent in the post-separation period-that is, the period from separation until they turned 18. Since respondents in our sample were adults at the time of the survey (between twenty-five and forty-six years old), these are retrospective reports on parental involvement. Respondents were asked how often the parent:

1. Talked with them about school or education

2. Helped with homework or school assignments

3. Took them on days out or participated in any hobbies with them

4. Took them to sports or participated in sports-related activities with them

5. Talked with them about personal matters

Respondents could choose between four answer categories ranging from very often to (almost) never. A fifth answer category allowed respondents to state that 
this item was not applicable. For fathers, between $4.9 \%$ (trips and hobbies) and $13.8 \%$ (sports) used the not applicable category. This was between $1.5 \%$ (talk about school and talk about personal matters) and $10.9 \%$ (sports) for biological mothers. We used version 1.1 of the OKiN data in which the answer categories not applicable and never are combined in the same category. It is not possible to say with absolute certainty what respondents meant if they used the category not applicable. However, behavior listed in every item is in theory possible for every parent-child tie. If a respondent stated that an item was not applicable, this was probably because there was limited contact with that parent, another parent already fulfilled this task, or it was not done at all. A robustness check in which respondents who answered not applicable to one or more items were removed from the sample did not show substantively different outcomes than the results presented in this paper.

The answer categories were coded from 0 (= never) to 4 (= always). The average score of the five items was calculated and standardized. The standardization was done separately for fathers and for mothers. This resulted in two scales, one for maternal involvement and one for paternal involvement. Children reported clearly higher levels of maternal involvement (see table 3). As a result, a comparison of absolute scores is in our opinion not meaningful. However, a robustness check with unstandardized dependent variables showed similar results. The Cronbach's alpha is .863 for the scale on maternal involvement and .836 for the scale on paternal involvement. To account for the skewed distribution in some involvement variables, we analyzed our data using percentile rank scores as dependent variables, but this did not change our findings. We also conducted separate analyses on educational involvement (items 1 and 2), involvement in leisure activities (items 3 and 4), and emotional support (item 5), but the results showed no differences between these types of involvement.

\section{Sibling variables}

The number of siblings of the anchors was extracted from Dutch administrative data. The OKiN data are the product of a register-based sample. As a result, we were able to trace back the respondents in the administrative registers. The first step was to use respondents' birth certificate information to match them to their (biological) parents. Second, to find stepparents, we used marriage and partner registrations. We examined whether there was a partner registered in the household of the biological parent when the respondent was fifteen years old. In addition, to include cohabiting couples, we checked whether there was another adult of the opposite sex, not a family member and between twenty-five and sixty years old, who was registered in the household of the biological parent when the anchor was fifteen years old. This person was considered to be the stepparent. This selection mechanism is not perfect. In rare cases, it is possible that an adult is registered in the household who is not the new partner of the parent and same-sex repartnering is not taken into account. However, a comparison between the respondents' reports on sibship size and the administrative data, which was only possible if the stepparent in childhood was still present at the 


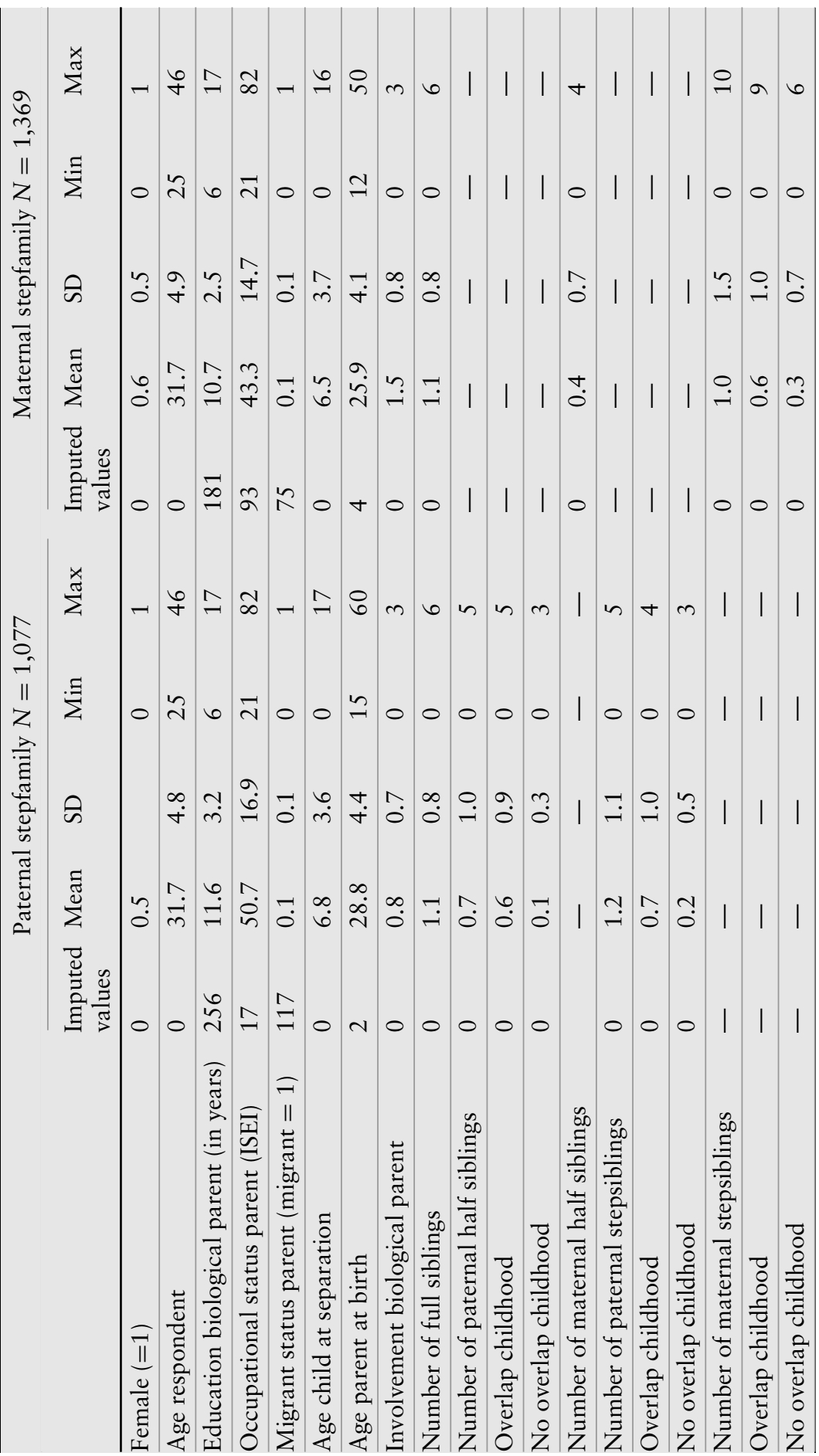

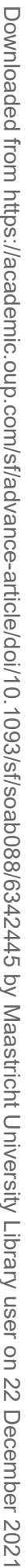


time of the questionnaire, suggests that false identifications of stepparents are uncommon. Another implication of our approach is that we do not make a distinction between marriage and cohabitation. This assumption is supported by the fact that cohabitation is widespread and relatively stable in the Netherlands, and differences between married and cohabiting couples are small (Statistics Netherlands 2019). Finally, an important advantage of this approach, in which we went back in time in the registers, is that it enabled us to include stepparents who disappeared because they separated from the biological parents of our respondents.

Altogether, our approach resulted in a complete parent network of both biological parents and their partners when the respondent was fifteen years old. Subsequently, to define the sibling structure in a family, information on all children of the parents in the parent network was retrieved from the registers (again based on birth certificate information). Those who had the same two parents on their birth certificate as the main respondent were considered full siblings. If they only shared one of their parents with the main respondent, they were considered half siblings. Finally, when they did not share a parent with the main respondent but their parent is the new partner of the parent of the main respondent, we called them stepsiblings. This unique approach made it possible to map all the anchor respondents' full siblings, and paternal and maternal half and stepsiblings.

The fact that we limited ourselves to stepparents who were present when the anchor was fifteen years old preserved a minimum level of homogeneity in our sample, since it ensured that we studied dilution as a result of siblings who were present when the respondent was a teenager. In doing so, we might have missed some stepparents, and as a result, stepsiblings who played a role during childhood. However, of all respondents whose father or mother had a new partner during childhood, $84 \%$ reported that this was the only other longterm relationship (at least two years) the parent had. For the other $16 \%$, it could be that another stepparent, and his/her children, were present in the anchor's life while this is not analyzed in our work. However, it should be kept in mind that this only affects our estimates of stepsiblings. Half siblings are always included in the analysis, due to their biological bond to the biological parent of the anchor.

We used two versions of the sibling variables. In the first version, the variable simply depicts the number of siblings of a certain sibling type (i.e., full siblings, paternal and maternal half siblings, and paternal and maternal stepsiblings). A second version was designed to control for the differentiation in exposure to different siblings. Some siblings spend most of the post-separation period in the same family, while others never actually compete for the same resources due to their age differences. This is especially common for half and stepsiblings. Especially when parents separate during childhood, large age differences between full siblings are uncommon. However, for half and stepsiblings, we expected there to be a considerable number of siblings who did not compete with respondents for resources, or only for a short period of time. Therefore, we created a weighted measure of half and stepsiblings. For each sibling tie, we calculated the number of years both siblings are minors and part of the same stepfamily. 
The post-separation period is not equally long for all respondents. Those who experienced a parental separation early in childhood reported over a longer period of time than those who experienced a separation later on. If a sibling lived with the respondent for two years, this might have been the full post-separation period for some siblings, while for others it was only a quarter of the postseparation time. In the first case, the influence of the sibling on the reported involvement would be much larger than in the latter case. Hence, we added a control for age of the child at separation. Finally, we conducted a robustness check with categorical sibling variables to examine whether our results were driven by the number of half or step siblings, or by differences between children with and without a step or half sibling. The results, presented in Table A2 of Appendix A, indicate that the largest differences occur between those who do not have a half or stepsibling and those who have at least one. However, there is an additional reduction of involvement for children with several half or stepsiblings, which suggests that the number of siblings matters. Therefore, we present the analyses with continuous variables as our main results.

The weighted sibling measure is based on the idea that siblings mostly compete for the same resources when they are both younger than eighteen years old and therefore in need of their parents' resources. It is important to keep in mind that our definition of an overlapping childhood is based on age differences and does not consider coresidence of siblings. Coresidence is not a requirement for competition and dilution in stepfamilies. Also children in another household can dilute resources of a parent if that parent is involved in the socialization of children in multiple households. Hence, a weighted measure based on age differences is more relevant, and feasible, for this study than a weighted measure based on coresidence.

\section{Controls}

We controlled for the age (mean centered), gender (female $=1$ ), and the age of the respondent at separation. In addition, controls were included for the education and occupational status of the parent whose involvement is analyzed. Previous research indicates that, on average, people with a higher socioeconomic status have fewer children and provide more resources to their children (Downey 1995). The educational variable was recoded into years of education and ranged from six years for primary education to seventeen years for parents who attained a university degree (Ganzeboom and Treiman 2017). Occupational status was coded with the ISEI scale (Ganzeboom, De Graaf, and Treiman 1992). Finally, we included controls for the migrant status of the parent, and the age of the parent when the respondent was born. A parent was considered a migrant when at least one of his/her parents was born abroad $(=1)$. A description of all variables can be found in table 3 .

\section{Method}

To take into account that the distributions of paternal and maternal involvement are probably not independent, we used seemingly unrelated regression to allow 
the error terms of the equation for maternal and paternal involvement to be correlated. An additional advantage of this approach is that it enables a direct significance test of the differences in coefficients of the sibling variables in the analysis in paternal and maternal involvement. However, the samples of maternal and paternal involvement are not balanced. That is, not all respondents in a maternal stepfamily are also in a paternal stepfamily, or the other way around. If we had used the standard approach to calculate a seemingly unrelated regression (the sureg command in Stata15), only the 533 respondents who were in a paternal stepfamily as well as a maternal stepfamily at the age of fifteen could have been taken into account. To avoid such a loss of cases, we followed the approach of Allen McDowell (2004), who showed how the xtgee command in Stata could be used to perform a seemingly unrelated regression with unbalanced samples. Finally, we used single regression imputation to impute the missing values of our variables on parents' educational attainment, occupational status, and migrant status. In addition to all variables in the model, a scale to measure the cultural capital of the parent, the current income of the parent, and the migrant status of the child was used for the imputation process. Single regression imputation is preferred over multiple imputation because it provides, in contrast to multiple imputation, a specific number to replace the missing value. This is a requirement for the seemingly unrelated regression we used in this study. The number of imputed values per variable can be found in table 3. A robustness check was conducted without imputation (i.e., listwise deletion), but this did not alter the substantive interpretation of our results. We conducted a robustness check with "regular" linear regressions in Appendix A (Table A1). This also enabled us to examine the role of categorical sibling variables (Table A2). There were no substantial differences whether linear regression or seemingly unrelated regression was used.

\section{Descriptive Statistics}

We start with a description of the sibling configurations in the stepfamilies in our sample. Figure 2 shows what percentage of respondents has at least one sibling in each category (full and (paternal/maternal) half and step). The descriptive statistics are provided separately for each sample. The figure indicates that in each sample, about $80 \%$ of the respondents have at least one full sibling. In addition, stepsiblings are somewhat more common in the maternal stepfamily ( $48 \%$ has at least one) than in the paternal stepfamily $(43 \%)$. This suggests that mothers more often marry a partner who already has children from a previous union. Finally, half siblings are more common in paternal stepfamilies $(38 \%)$ than in maternal stepfamilies $(31 \%)$.

Figure 3 describes how many respondents have siblings whose childhood did not overlap with their own childhood. That is, there was never a moment in which the respondent and this sibling were both younger than eighteen years old and part of the same stepfamily. In these cases, it can be assumed that there was little competition, so these siblings were automatically excluded in 
Figure 2. Percentage of respondents with at least one sibling in the category. Split into maternal and paternal stepfamilies.

\section{A. Maternal stepfamily}

100

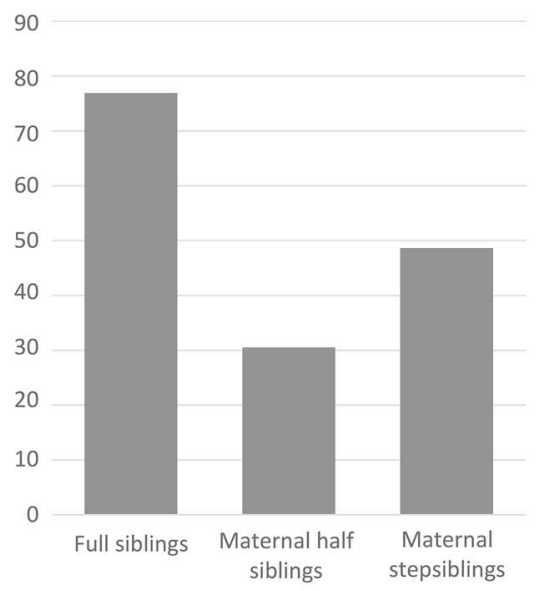

B. Paternal stepfamily

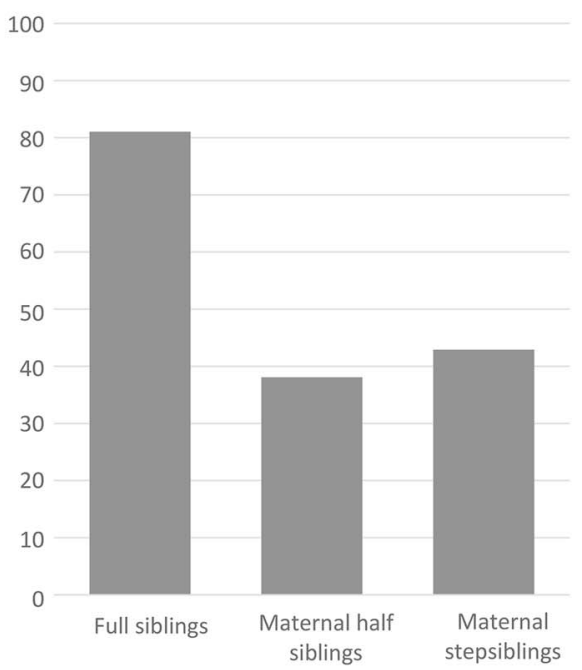

Figure 3. Percentage of half and stepsiblings with and without overlapping childhoods.

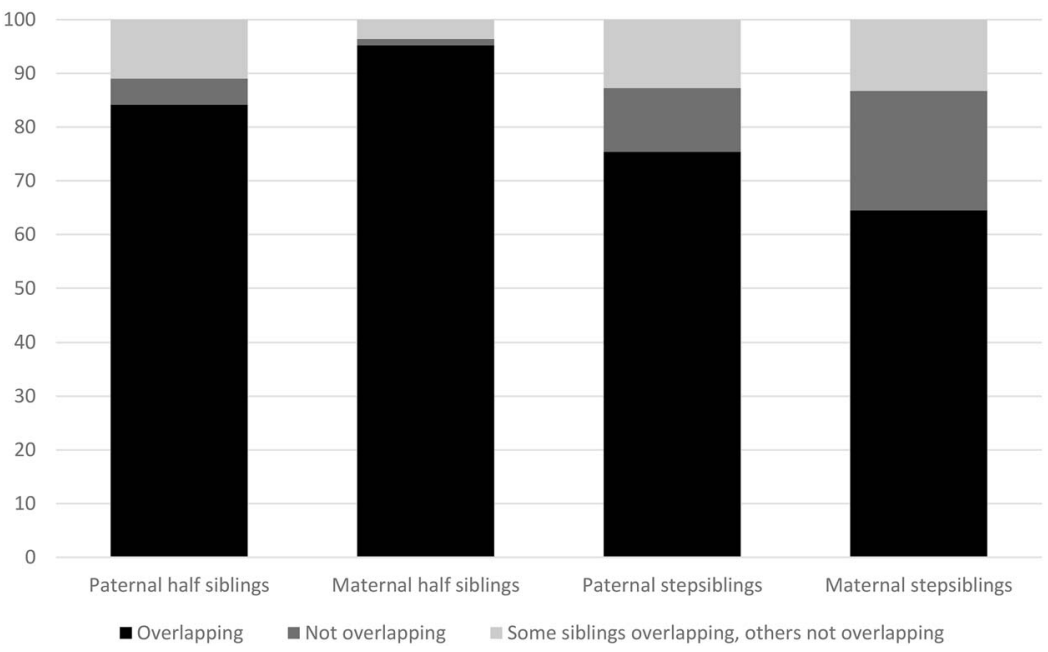

the weighted version of our sibling variable (weighted by factor 0 ). About $16 \%$ of the respondents in paternal stepfamilies have one or more half siblings who are at least eighteen years younger (no overlapping childhoods). In maternal stepfamilies, about $5 \%$ has at least one half sibling without overlapping childhoods. Half siblings with large age differences are less common in maternal stepfamilies because the restrictions of female fertility limit the possibilities for women to have large age differences between their biological children. Large 
age differences are more common among stepsiblings than half siblings. In the maternal stepfamily, about $35 \%$ of the respondents have at least one stepsibling whose childhood did not overlap with their own childhood. This is $25 \%$ in the sample of paternal stepfamilies. The gender difference is the result of age differences between stepfathers and stepmothers. Women are more likely to have an older partner. Hence, stepfathers are on average older than stepmothers and therefore also more likely to already have children from a previous union. Altogether, these descriptive statistics support our statement that large age differences between siblings are common in stepfamilies.

\section{Results}

The results of our analyses are presented in tables 4 and 5. Table 4 includes our main results, while table 5 presents the analysis with weighted sibling variables. Each table consists of two models: one on maternal involvement (Model 1) and one on paternal involvement (Model 2).

First, we discuss the dilution of maternal resources (Model 1 in table 4). Based on the biology hypothesis, it is expected that full siblings and maternal half siblings dilute maternal resources more strongly than maternal stepsiblings. In line with our expectations, the analysis shows a negative and statistically significant association between the number of full siblings and maternal involvement $(-.216)$. Since our dependent variable is standardized, this indicates that with every additional full sibling, maternal involvement drops about a quarter of a standard deviation. In the same model, a small and statistically insignificant association is found between the number of stepsiblings and maternal involvement (.024). These findings are in line with the biology hypothesis. However, we also expected a negative association between the number of maternal half siblings and maternal involvement with a coefficient similar in size to the coefficient of the number of full siblings. Although the coefficient of half siblings is negative $(-.059)$, it is much smaller than the coefficient of the number of full siblings and not statistically significant. This suggests that maternal half siblings hardly dilute maternal resources.

Second, we discuss the dilution of paternal resources. Two alternative hypotheses are formulated. Based on the biology hypothesis, we expected full siblings and half siblings to dilute paternal resources more strongly than stepsiblings. In contrast, in the swapping family hypothesis, we hypothesized that paternal half and stepsiblings would dilute resources more strongly than full siblings. Finally, a third possibility was a synthesis between both hypotheses. That is, dilution is strongest when there is a biological tie between the father and the child as well as beneficial opportunity structures-based on the most common kinkeeping and coresidence patterns. The results are presented in Model 2 of table 4. The analysis indicates a statistically significant negative association between all sibling types-full, half, and step-and paternal involvement. According to the analysis, the coefficient of paternal half siblings is the largest $(-.149)$ followed by full siblings $(-.119)$ and paternal stepsiblings 


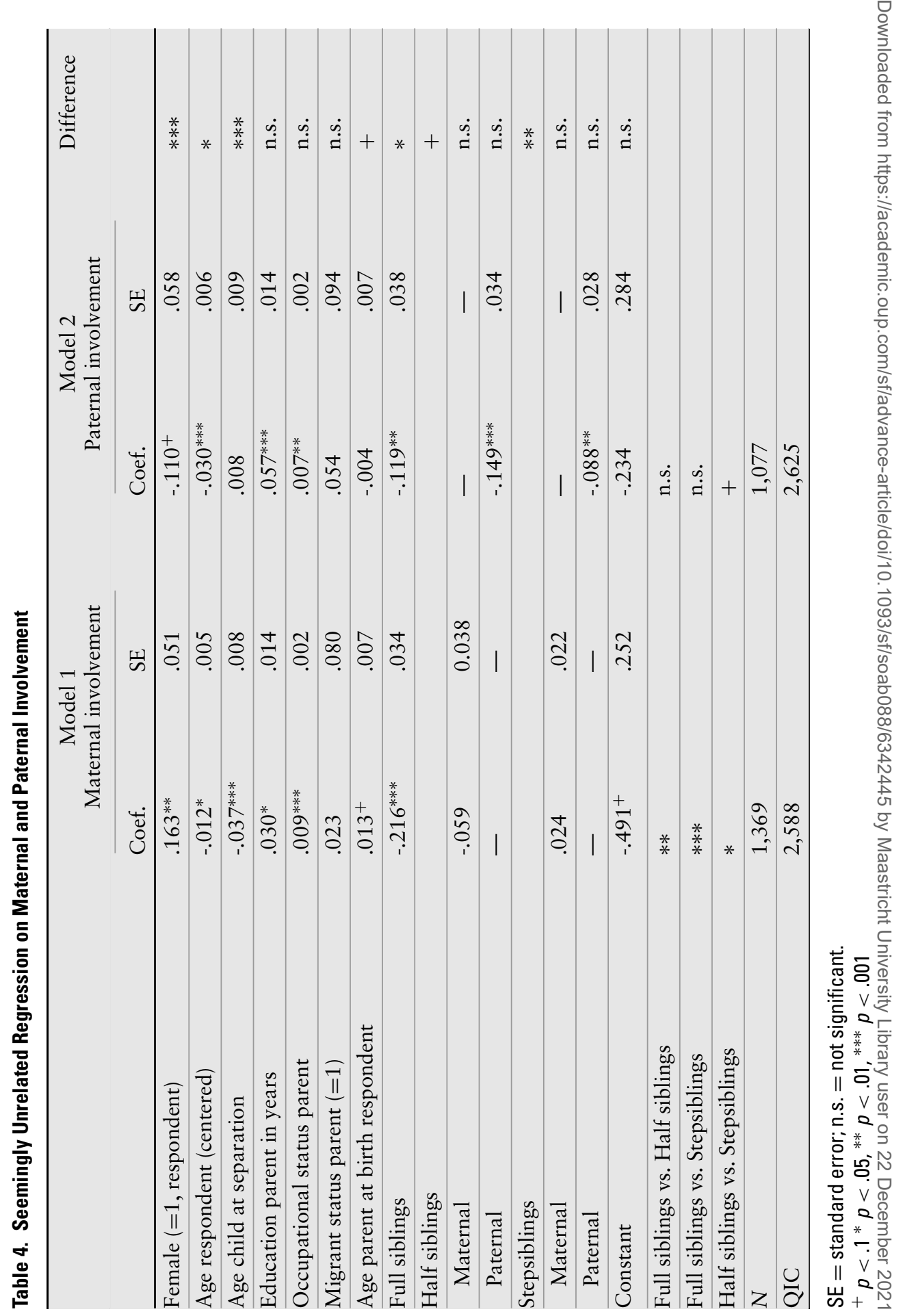


Table 5. Seemingly Unrelated Regression on Maternal and Paternal Involvement with Weighted Sibling Variables

\begin{tabular}{|c|c|c|c|c|}
\hline & \multicolumn{2}{|c|}{$\begin{array}{c}\text { Model } 1 \\
\text { Maternal involvement }\end{array}$} & \multicolumn{2}{|c|}{$\begin{array}{l}\text { Model } 2 \\
\text { Paternal involvement }\end{array}$} \\
\hline & Coef. & SE & Coef. & SE \\
\hline \multicolumn{5}{|c|}{ Half siblings (weighted) } \\
\hline Paternal & - & - & $-.021^{* * *}$ & .005 \\
\hline Maternal & .004 & .005 & - & - \\
\hline \multicolumn{5}{|c|}{ Stepsiblings (weighted) } \\
\hline Paternal & - & - & -.008 & .005 \\
\hline Maternal & .006 & .004 & - & - \\
\hline Constant & $-.609^{* * *}$ & .237 & $-.558^{*}$ & .265 \\
\hline$N$ & 1,369 & & 1,077 & \\
\hline QIC & 2,585 & & 2,623 & \\
\hline
\end{tabular}

Note: Controlled for gender child (female $=1$ ), age child (mean centered), educational attainment parent, occupational status parent (ISEI), migrant status parent (migrant $=1$ ), age of the parent when respondent was born, age of the child at parental separation, and the number of full siblings. $\mathrm{SE}=$ standard error.

${ }^{*} p<.05,{ }^{* *} p<.01,{ }^{* * *} p<.001$

$(-.088)$. Only the difference between the coefficients on half and stepsiblings is statistically significant. Altogether, these findings support our ideas of a synthesis. Fathers do not completely shift their attention to the children in their second union (swapping family hypothesis) since full siblings still dilute resources. However, they also do not focus solely on biological offspring, as can be derived from the dilution as a result of the presence of paternal stepsiblings. Dilution due to the presence of paternal half siblings is predicted by the existence of biological ties as well as a kinkeeping tie between the father and the child, and this is also the largest coefficient. This matches our expectation that both hypotheses, as presented in table 2, predict dilution. However, although the difference between full and paternal half siblings is relatively large, it is not statistically significant.

The idea of a synthesis also provides guidance when the analyses on maternal and paternal resources are compared. The stars in the last column of table 4 indicate whether the difference between the coefficients across models for maternal and paternal resources is statistically significant. To start, mothers share a biological tie as well as a kinkeeping and coresidence tie with the full siblings of our respondents, while fathers only have a biological tie to full siblings. Hence, our finding that the dilution due to the presence of full siblings is stronger for maternal resources compared to paternal resources is in line with the idea of a synthesis. Similarly, it is in line with our expectations that the coefficient of stepsiblings is significantly larger when paternal resources are studied than when maternal resources are used as an outcome variable. This is based on the logic 
that fathers of our respondents are more likely to share a kinkeeping tie with their stepchildren and spend more time with them in a mutual household. The only deviating finding is the significant difference between the coefficients of half siblings. As both parents share a biological tie as well as a kinkeeping tie with the half siblings of our respondents, the coefficients were expected to be similar in size. However, because of the aforementioned lack of dilution of maternal resources due to the presence of maternal half siblings, this is not the case. In summary, while fathers distribute their resources across all of their children, mothers seem to use their resources to limit the negative impact of sibship size for the children from their first union.

Finally, we weighted the variables on half and stepsiblings by the number of years the respondent and the sibling lived together in the same family while they were both minors $(<18)$. The results are presented in table 5 . The coefficients of the sibling variables indicate the change in involvement (in standard deviations) if a respondent and sibling spend one more year in the same stepfamily. For example, the involvement of fathers decreases with a quarter of a standard deviation $(-.210)$ if one half sibling shares ten years of the post-separation time together with the main respondent $(-.021 * 10=-.210)$. In general, the findings are similar to the findings in table 4 . For maternal half and stepsiblings, no evidence for the dilution of resources is found while paternal half siblings dilute paternal resources. However, in the weighted model, the coefficient of paternal stepsiblings is no longer statistically significant. Finally, the Quasilikelihood under Independence Model Criterion (QIC) of Models 1 and 2 in table 5 (weighted) is lower than the QIC for the same models in table 4 (unweighted). This is in line with the spacing hypothesis and suggests that controlling for large age differences, and the opportunity to compete for resources, improves the model fit when resource dilution is studied.

\section{Discussion and Conclusion}

This study provides the first comprehensive overview of the dilution of parental resources in stepfamilies. The focus on the unique characteristics of stepfamilies is an important addition to the literature on resource dilution because there are theoretical reasons to assume that full, half, and stepsiblings do not dilute resources to the same extent. The bias that might occur when these differences between sibling types are ignored has grown due to the increasing prevalence of separation and divorce. We distinguished two main mechanisms that could determine why parents in stepfamilies invest more in some children than in others. First, based on the societal norms of biology as well as evolutionary theory, we expected parents to invest more in their biological offspring. Second, based on kinkeeping mechanisms and the opportunity structures determined by the most common coresidence arrangements, we stated that investment patterns might be gendered. Rather than rejecting one set of mechanisms while supporting the other, our results indicate a synthesis. The dilution of resources is strongest when there is a biological bond between the parent and the child as well as 
a high likelihood of a kinkeeping tie and coresidence. Based on this logic, it is unsurprising that our findings indicate that full siblings dilute maternal resources more strongly than paternal resources. Similarly, it is in line with our expectations that the dilution of stepsiblings is significantly stronger when paternal resources are studied than when maternal resources are used as an outcome variable. Fathers are more likely than mothers to reside with their stepchildren, and fathers more often have partners who function as a kinkeeper to support the relationship with their stepchildren. In the weighted version of our sibling variables, the coefficient of stepsiblings was no longer statistically significant. The presence of stepchildren who are minors in the household might result in more family-oriented fathers, and this could also increase the investments in other children. Since the weighted sibling variable solely includes stepchildren who are minors, the dilution of those siblings might be balanced by the more child-friendly environment. However, more research is needed to fully comprehend this finding.

Another unanticipated finding was the absence of an association between the number of half siblings and maternal involvement. This finding suggests that maternal half siblings do not dilute resources despite the existence of a biological bond as well as coresidence and a kinkeeping tie. Compensatory behavior might explain the small coefficients and absence of statistical significance. Previous studies have shown that (highly educated) mothers are able to compensate for the negative consequences of separation on children's well-being and educational attainment (Bernardi and Boertien 2017; Fischer 2007; Mandemakers and Kalmijn 2014). It is possible that compensatory behavior is also activated during other changes in the family structure that might harm the well-being of the child, such as the birth of a half sibling. For example, mothers might decide to reduce working hours after the birth of a half sibling. Additionally, it is possible that stepfathers increase their involvement in family life after the birth of a half sibling (their biological child), which might enable mothers to minimize the reduction of involvement in the lives of the children from their first union. Compensatory behavior might play a role, also when material resources are studied. For example, parents can decide to work more hours to increase their income or cut some of their expenses when a child is born. In this way, they increase the level of material resources and limit the reduction of resources children might otherwise experience when a sibling is born. However, compensatory behavior is usually easier for nonmaterial resources, such as when parents limit their leisure time or reduce their employment hours to be able to spend more time with their children. As a result, it is likely that compensatory behavior has a larger influence on the dilution of nonmaterial resources. It is beyond the scope of this study to examine how large the role of compensatory behavior is exactly. However, future studies could make a useful contribution to the literature by increasing our understanding of compensatory behavior after the birth of (half) siblings.

To understand why the dilution due to the presence of full siblings does not vanish as a result of compensatory behavior, it can be helpful to keep in mind that the presence of a half sibling signals, in contrast to the presence of full siblings, an actual change in family structure during the post-separation period 
when the respondent is reporting the involvement of the parents. Moreover, it could be argued that full siblings are always more direct competitors than half siblings. Finally, compensatory behavior is less clearly visible in the results on paternal resources. Unlike mothers, fathers are more likely to distribute resources across two households, and this interferes with the likelihood of compensatory behavior. In the more recent cohorts, residence arrangements are more diverse, with a greater likelihood of children living with their father on a daily basis, so the dilution patterns might change accordingly.

Altogether, this study offers a renewed perspective on the sibship size literature. Due to the question on the causal nature of sibship size effect, a strong methodological focus has preoccupied this field of research in the recent past, but results are mixed. Meanwhile, sibship size is still frequently studied and used as a control variable. Although it is important to stress that this study does not aim to solve or add to the causality debate, our findings are certainly relevant for this strand of the literature. First, the causality debate mostly focuses on educational attainment as an outcome variable. Our outcome variable, parental involvement, offers a more direct test of the assumed mechanism that children receive less in terms of parental resources if the number of siblings increases. Second, this study indicates that some siblings in separated families do not dilute resources at all, while others dilute resources strongly. Moreover, siblings do not dilute resources of fathers and mothers in the same way. Since the number of children in stepfamilies is steadily increasing, results could be biased if the distinctions between sibling types or paternal and maternal resources are not thoroughly operationalized. This bias continues to exist when distinctions between sibling types and mothers and fathers are not made, also in the advanced methods that aim to reveal the causal nature of sibship size effects.

Despite the important contribution made by this study, there are also some limitations. Most importantly, our study is based on retrospective reports of adults (age 25-46) about parental involvement during their childhood. To some extent, a potential retrospective bias is probably cushioned by the way the questions in the OKiN data are designed. Respondents mostly answer questions on concrete events (e.g., sports, hobbies, help with homework) rather than subjective events (e.g., feelings), using general frequencies (i.e., never, rarely, sometimes, always) rather than precise frequencies (e.g., how many times a week). It has been shown that people are better able to report accurately if questions are designed in this way (Hardt and Rutter 2004). If a systematic bias occurs nevertheless, it is likely to be due to the current relationship between parents and children. Respondents who at the time of the survey (when they were adults) had a poor relationship with a parent might look back on their childhood in more negative ways, which would result in disproportionally low reports on parental involvement. Yet, it is difficult to examine how large this bias would be. Closeness and involvement are two concepts, which both reflect the relationship between parents and children. As a result, a positive association between closeness and involvement is not surprising and also not necessarily problematic. Yet, we argue that a retrospective bias based on closeness has little implication for our conclusions. Our hypotheses and conclusions are based on 
a comparison between sibling coefficients. We argue that some coefficients are larger than others because some siblings dilute resources more strongly than others. These comparisons would only be biased if current closeness was also strongly correlated with the number of siblings. That is, if such a correlation between the number of siblings and closeness existed, it would mean that the coefficients of sibling types would be affected by the retrospective bias in different ways, and so our comparisons between coefficients would also be biased. Yet, the correlations between the number of siblings and current closeness never exceed $r=.12$. In other words, there is no evidence that current closeness has a strong effect on the sibling coefficients. As a result, our comparisons between sibling variables hold. A second limitation is that our measure of parental involvement might suffer from endogeneity. Answer categories such as "often" and "sometimes" are to some extent subjective, and it is possible that children in large families have a lower threshold to refer to the investments of their parents as "often" simply because they are used to lower levels of investments. If that is the case, it could be said that children in large families report higher levels of investments than they objectively receive. Hence, this endogeneity problem would result in an underestimation of our coefficients. This could mean that the absence of some expected sibling effects (such as maternal half siblings) is (partly) the result of endogeneity issues, though the coefficients we found in this study are most likely accurate and dilution might in reality be even larger.

Finally, we have not included any measure of coresidence in our analysis. Both the coresidence between parents and children and the coresidence of siblings could influence the dilution patterns in our data. Measuring coresidence in stepfamily structures is a complex task. After a separation, children often have some type of schedule to ensure that they either live part time with both biological parents (one week with one parent and the next with the other, for example), or regularly visit/stay over at the biological parent they do not live with (once a month, for example). This detailed information is not available for all siblings in the OKiN data and is also not detectable based on register data. Even if you simply took the address where children are registered to get a crude measure of coresidence, this would not be very informative. Most children are only registered in the household of their mother after a separation, especially in the cohorts we studied (1971-1991), but there will have been a large variance in how much time they spent with their father and each other. Because of these complexities, we relied on the most common patterns of coresidence to predict (gendered) dilution patterns. However, especially in more recent cohorts, the coresidence patterns are more diverse, and it would be a useful next step in the literature to find a good way to measure coresidence in stepfamilies and to apply this in a study on the dilution of resources in stepfamilies.

In this paper, we have brought together the literature on family complexity and resource dilution and have described the dilution patterns in stepfamilies. Our findings open up a new field of research questions for future studies. For example, stepparents could also invest resources and thus add to the resources children receive during childhood. More knowledge about the investments of 
stepparents, and how they are related to sibship size, could help us to get a more complete picture of the parental resources that children receive in stepfamilies. Another example is the interplay between the investments of different parent types. If one parent invests more, there might be less need and opportunity for the other parent to invest in the child. In other words, it is likely that the investments of different parent types are dependent on one another. The use of seemingly unrelated regression analysis in this study has corrected for some of these interdependencies, but it would be interesting to study in more detail how the involvement of different parents is dependent on each other. Finally, it would be useful to examine if findings are similar when the dilution in material resources is examined. Although the general mechanisms are similar for material and nonmaterial resources, it is possible that there are differences. In particular, the role of compensatory behavior might be smaller when material resources are studied. Data sources that include longitudinal data, more time-specific dependent variables, and detailed measures of coresidence can help us to improve the literature. Based on these data innovations, future studies could assist in unraveling the complex link between family structure and the availability of resources for children.

To sum up, this study is the first to provide a systematic overview of the role of sibship size in the dilution of nonmaterial parental resources in complex family configurations. Results indicate that there are important differences between full, half, and stepsiblings and the dilution of maternal and paternal resources. Hence this paper illustrates the complexity of resource dilution due to sibship size in stepfamilies and emphasizes that ignoring these complexities might bias results. Future research should distinguish between sibling types as well as separate paternal and maternal resources to get an accurate picture of resource dilution in modern family life.

\section{Supplementary Material}

Supplementary material is available at Social Forces online, http://sf.oxfordjou rnals.org/.

\section{About the Authors}

Suzanne G. de Leeuw is a researcher at Education Lab/Research Centre for Education and the Labour Market (ROA) at Maastricht University. This study is based on a chapter in her dissertation "The Intergenerational Transmission of Educational Attainment after Divorce and Remarriage," which she defended on April 1, 2021 at the University of Amsterdam. She is interested in (educational) inequalities and family sociology.

Matthijs Kalmijn is a full professor of Sociology at the Netherlands Interdisciplinary Demographic Institute (NIDI)-KNAW/University of Groningen. His main research fields are family, life courses, and intergenerational relationships. He was co-director of several large-scale surveys in the Netherlands, including 
the survey Parents and Children in the Netherlands (OKiN), the Netherlands Kinship Panel Study (NKPS), and the Netherlands Longitudinal Lifecourse Study (NELLS). Kalmijn has a PhD from UCLA (1991). He is principal investigator of the ERC Advanced Grant Intergenerational Reproduction and Solidarity in an Era of Family Complexity.

Ruben van Gaalen is a senior researcher at Statistics Netherlands and a professor by special appointment of register analyses of life course dynamics at the Sociology Department, Faculty of Social and Behavioural Sciences, University of Amsterdam. He is interested in demographic behavior, life course dynamics, parent-child relationships, and social inequality.

\section{References}

Alvergne, Alexandra, Charlotte Faurie and Michel Raymond 2009. "Father-Offspring Resemblance Predicts Paternal Investment in Humans." Animal Behaviour 78(1):61-9. 10.1016/j.anbehav.2009.03.019.

Benner, Aprile D., Alaina E. Boyle and Sydney Sadler 2016. "Parental Involvement and Adolescents' Educational Success: The Roles of Prior Achievement and Socioeconomic Status." Journal of Youth and Adolescence 45(6):1053-64. 10.1007/s10964-016-0431-4.

Bernardi, Fabrizio and Diederik Boertien 2017. "Explaining Conflicting Results in Research on the Heterogeneous Effects of Parental Separation on Children's Educational Attainment According to Social Background." European Journal of Population 33(2):243-66. 10.1007/s10680-017-9417-5.

Black, Sandra E., Paul J. Devereux and Kjell G. Salvanes 2005. "The More the Merrier? The Effect of Family Size and Birth Order on Children's Education." The Quarterly Journal of Economics 120(2):669-700. 10.1093/qje/120.2.669.

Blake, Judith 1989. Family Size and Achievement Vol. 3: Berkeley: University of California Press.

Cherlin, Andrew 1978. "Remarriage as an Incomplete Institution." American Journal of Sociology 84(3):634-50.

Conley, Dalton and Rebecca Glauber 2006. "Parental Educational Investment and Children's Academic Risk Estimates of the Impact of Sibship Size and Birth Order from Exogenous Variation in Fertility." Journal of Human Resources 41(4):722-37. 10.3386/w11302.

Leonardo, Di and Micaela 1987. "The Female World of Cards and Holidays: Women, Families, and the Work of Kinship." Signs: Journal of Women in Culture and Society 12(3):440-53.

Downey, Douglas B. 1995. "When Bigger Is Not Better: Family Size, Parental Resources, and Children's Educational Performance." American Sociological Review 60(5):746-61.

Emlen, S.T. 1995. "An Evolutionary Theory of the Family." Proceedings of the National Academy of Sciences of the United States of America 92(18):8092-9.

Fischer, Tamar 2007. "Parental Divorce and Children's Socio-Economic Success: Conditional Effects of Parental Resources Prior to Divorce, and Gender of the Child." Sociology 41(3):475-95.

Ganzeboom, Harry B. G., \& Donald J. Treiman. 2017. "International Stratification and Mobility File." http:// www.harryganzeboom.nl/ismf/eduxx/netxx_edu.htm

Ganzeboom, Harry B.G., Paul M. de Graaf and J. Treiman Donald 1992. "A Standard International Socio-Economic Index of Occupational Status." Social Science Research 21(1):1-56. 10.1016/0049-089X(92)90017-B. 
Hardt, Jochen and Michael Rutter 2004. "Validity of Adult Retrospective Reports of Adverse Childhood Experiences: Review of the Evidence." Journal of Child Psychology and Psychiatry 45(2):260-73. 10.1111/j.1469-7610.2004.00218.x.

Kalmijn, Matthijs 2013. "Adult Children's Relationships with Married Parents, Divorced Parents, and Stepparents: Biology, Marriage, or Residence?" Journal of Marriage and Family 75(5):1181-93.

Kalmijn, Matthijs 2014. "Adult Intergenerational Relationships". In Sociology of Families, edited by Treas, Judith, Scott, Jacqueline, Richards, Martin, pp. 385-403: Hoboken, New Jersey: Wiley Online Library.

Kalmijn, Matthijs, Katya Ivanova, Ruben van Gaalen, Suzanne G. de Leeuw, Kirsten van Houdt, Frederique van Spijker and Maaike Hornstra 2018. "A Multi-Actor Study of Adult Children and their Parents in Complex Families: Design and Content of the OKiN Survey." European Sociological Review. 34(4): $452-70$.

Li, Hongbin, Junsen Zhang and Yi Zhu 2008. "The Quantity-Quality Trade-off of Children in a Developing Country: Identification Using Chinese Twins." Demography 45(1):223-43.

Lu, Yao and Donald J. Treiman 2008. "The Effect of Sibship Size on Educational Attainment in China: Period Variations." American Sociological Review 73(5):813-34. 10.1177/000312240807300506.

Mandemakers, Jornt J. and Matthijs Kalmijn 2014. “Do Mother's and Father's Education Condition the Impact of Parental Divorce on Child Well-Being?" Social Science Research 44:187-99.

McDowell, Allen 2004. "From the Help Desk: Seemingly Unrelated Regression with Unbalanced Equations." The STATA Journal 4(4):442-8.

McNeal, Ralph B. 1999. "Parental Involvement as Social Capital: Differential Effectiveness on Science Achievement, Truancy, and Dropping out." Social Forces 78(1):117-44.

Rosenthal, Carolyn J. 1985. "Kinkeeping in the Familial Division of Labor." Journal of Marriage and the Family 47(4):965-74.

Schnettler, Sebastian and Anja Steinbach 2011. “How Do Biological and Social Kinship Play Out within Families in the US? An Evolutionary Perspective on Perceived Parental Care and Closeness in Adolescents." Zff-Zeitschrift Für Familienforschung/Journal of Family Research 23(2).

Suitor, J. Jill, Jori Sechrist and Karl Pillemer 2007. "When Mothers Have Favourites: Conditions under which Mothers Differentiate among their Adult Children." Canadian Journal on Aging/La Revue Canadienne Du Vieillissement 26(2):85-99.

Statistics Netherlands 2019. "Half of cohabitants still together after 15 years." Retrieved from: https:// www.cbs.nl/en-gb/news/2019/06/half-of-cohabitants-still-together-after-15-years

Tach, Laura 2015. "Social Mobility in an Era of Family Instability and Complexity." The Annals of the American Academy of Political and Social Science 657(1):83-96.

Van Houdt Kirsten, Matthijs Kalmijn and Katya Ivanova 2018. "Family Complexity and Adult Children's Obligations: The Role of Divorce and co-Residential History in Norms to Support Parents and StepParents." European Sociological Review 34(2):169-83.

Van Gaalen, R., K. Van Houdt and A. Poortman 2019. "Trouwen, kinderen krijgen en (echt)scheiden naar opleidingsniveau Demografische beslissingen binnen huishoudens aan het begin van de 21e eeuw." Statistics Netherlands.

Wiemers, Emily E., Judith A. Seltzer, Robert F. Schoeni, V. Joseph Hotz and Suzanne M. Bianchi 2019. "Stepfamily Structure and Transfers between Generations in US Families." Demography 56(1):229-60. Workman, Joseph 2017. "Sibling Additions, Resource Dilution, and Cognitive Development during Early Childhood." Journal of Marriage and Family 79(2):462-74. 